\title{
Legal compliance of the electronic Bill of Lading
}

\author{
Quentin Schiltz \\ Rotterdam Business School \\ Rotterdam University of Applied \\ Sciences \\ Rotterdam, The Netherlands \\ 0976920@hr.nl
}

\begin{abstract}
The Bill of Lading (BOL) is one of the most important documents in international trade. In addition to its main functions, such as evidence of contract and the receipt of goods, the document of title function plays an equally essential role and contributes to the importance of the BOL. However, the rapid developments and changes of international trade have highlighted the limits of the traditional BOL. Its flaws, such as slowness, the possibility of fraud and high relative costs have often been revealed as problematic. The electronic Bill of Lading (eBOL), which represents the legal and functional equivalent of the paper-BOL, was thus created to eliminate these abovementioned flaws. Nevertheless, the global implementation of the eBOL is not realizable yet, due to the existence of a range of barriers. The main barrier, which will be further discussed in this paper, is the lack of knowledge regarding already in place standards and regulations. Hence, this paper sets out to discuss existing standards and regulations such as the Rotterdam Rules, the Model Law on Electronic Transferable Records and the Electronic Data Interchange and will examine to what extent they can support the implementation of an eBOL.
\end{abstract}

Keywords - Bill of Lading, electronic Bill of Lading, legal equivalence, digitalisation, EDI, Rotterdam Rules, Model Law on Electronic Transferable Records

\section{INTRODUCTION}

Ever since the Bill of Lading (BOL) was introduced in the $13^{\text {th }}$ century, it has become one of the most important documents in modern commerce and international trade. It is an essential legal document for proving the global shipping of commercial goods. The BOL is a document which evidences a contract of carriage by sea, the receipt of cargo and document of title, which guarantees that the importing party receives the cargo. In addition to that, it is also critical in foreign trade financing in order for the exporting party to receive the payment. However, the advance in globalisation and shift in customer demand, indicate the limitations of the paper-based BOL. Such limitations are slowness, considerable costs and the possibility of misuse by involved parties, which will be further elaborated in this paper. Considering the rapid development in logistics and technology, the electronic BOL (eBOL) seems to represent a better alternative. The BOL has been created particularly to eliminate the abovementioned flaws of the traditional version. However, the biggest challenge for its successful implementation is the lack of knowledge of already existing standards and regulations which support the digitalisation of the BOL.

This paper will first examine the elements of the BOL and the three critical functions. Secondly, in what follows, this paper will analyse the challenges the BOL is facing and thirdly, why the global implementation of the eBOL is not realisable yet. Lastly, this paper will establish four criteria and will present one standard and two regulations which support its global implementation.

\section{BILL OF LADING}

\section{A. Elements of the Bill of Lading}

The structure of the BOL can change from company to company and between countries. Even though not all BOLs are identical, it is necessary to provide all the essential elements every BOL has in common. Therefore, this paper takes into account the Top 20 carriers, as they operate $80 \%$ of all container shipments and present a nearly identical BOL [1]. Their identical structure is due to them using the Hague-Visby Rules [2], which is a set of rules for the international carriage of goods by sea, as the starting point to create their BOL. Furthermore, the BOL of the "International Federation of Freight Forwarders Associations" (FIATA), which represents the freight forwarder industry and covers approximately 40000 forwarding and logistics firms, will be analysed too [3]. The result is that the FIATA BOL and the Top 20 carriers BOL are similar.

The BOLs contain the elements consignee, shipper, notify party, vessel name and voyage number, port of loading and port of discharge, place of receipt and place of delivery, container numbers, seal numbers and marks, description of package and goods, gross weight, measurement and signature. Table 3 presents and explains 11 elements that can be found on the abovementioned BOLs.

TABLE 1. ELEMENTS OF THE BOL

\begin{tabular}{|c|cl|}
\hline $\begin{array}{c}\text { Element of } \\
\text { BOL }\end{array}$ & \multicolumn{1}{c|}{ Description } \\
\hline Shipper & $\bullet \begin{array}{l}\text { Owner of the goods (exporting company) } \\
\text { Business Name and Business addresses } \\
\text { (matching with Letter of Credit) }\end{array}$ \\
\hline Consignee & $\bullet \begin{array}{l}\text { Receiver of the goods (importing company) } \\
\text { Determines whether BOL is negotiable or not } \\
\text { Negotiable when marked: To Order or To Order } \\
\text { of }\end{array}$ \\
\hline $\begin{array}{c}\text { Notify } \\
\text { Party }\end{array}$ & $\bullet \begin{array}{l}\text { If consignee field involves "to order" or blank } \\
\text { endorsed BOL }\end{array}$ \\
$\begin{array}{l}\text { Once arrived at the port of discharge, carrier is } \\
\text { notifying the company stated on this field (mainly } \\
\text { importer's contractual logistics operator) } \\
\text { Notify Party has no effect on title of the goods }\end{array}$ \\
$\begin{array}{c}\text { Vessel } \\
\text { Vome and } \\
\text { Vumber }\end{array}$ & $\bullet \quad \begin{array}{l}\text { When booking a container for the shipment, } \\
\text { Vessel name and Voyage number are defined }\end{array}$ \\
\hline
\end{tabular}




\begin{tabular}{|c|c|}
\hline $\begin{array}{c}\text { Element of } \\
\text { BOL }\end{array}$ & Description \\
\hline $\begin{array}{c}\text { Port of } \\
\text { Loading } \\
\text { and Port of } \\
\text { Discharge }\end{array}$ & $\begin{array}{l}\text { - } \quad \text { Port of Loading: where carriage starts } \\
\text { - } \quad \text { Port of Discharge: where carriage ends } \\
\text { - Defines carrier's responsibility period }\end{array}$ \\
\hline $\begin{array}{l}\text { Place of } \\
\text { Receipt and } \\
\text { Place of } \\
\text { Delivery } \\
\end{array}$ & $\begin{array}{l}\text { When either one of place of receipt or place of } \\
\text { delivery is completed: Door-to-Door delivery } \\
\text { (multimodal shipments) }\end{array}$ \\
\hline $\begin{array}{l}\text { Container } \\
\text { Numbers, } \\
\text { Seal } \\
\text { Numbers } \\
\text { and Marks }\end{array}$ & $\begin{array}{l}\text { - Container number: unique reference number } \\
\text { (Enables traceability of the freight container) } \\
\text { - Seal Number: Each container is sealed with a } \\
\text { secure seal by shipper } \\
\text { Marks: tare weight of container (inserted by } \\
\text { carrier) and container type }\end{array}$ \\
\hline $\begin{array}{l}\text { Descriptio- } \\
\quad \text { n of } \\
\text { Package } \\
\text { and Goods }\end{array}$ & $\begin{array}{l}\text { General description of goods, package types, } \\
\text { package amount } \\
\text { Any additional information: HS code, Letter of } \\
\text { credit number, etc. }\end{array}$ \\
\hline $\begin{array}{l}\text { Gross } \\
\text { Weight }\end{array}$ & $\begin{array}{l}\text { - Total weight of the goods + packaging materials } \\
\text { inside the container }\end{array}$ \\
\hline $\begin{array}{l}\text { Measure- } \\
\text { ment }\end{array}$ & $\begin{array}{l}\text { - Gross volume of the consignment (Usually goods } \\
\text { fill containers completely) }\end{array}$ \\
\hline Signature & - Proof of authenticity \\
\hline
\end{tabular}

\section{B. Functions of the Bill of Lading}

The BOL is a crucial document in modern commerce and international trade and according the Hamburg Rules serves three main functions [4]. It is defined as "a document which evidences a contract of carriage by sea and the taking over or loading of the goods by the carrier, and by which the carrier undertakes to deliver the goods against surrender of the document." [4]. Firstly, the BOL is a conclusive receipt of the cargo, meaning that it acknowledges that the goods have been loaded. Secondly, it evidences the terms of the contract of carriage between the carrier and the shipper when the goods are loaded on board. Finally, the document of title enables the transfer of ownership of the cargo to a third party. The next section elaborates these three different functions.

\section{1) Receipt of Goods}

The receipt of cargo serves three purposes, namely the proof that the carrier received the goods, provision of information about the cargo and evidence for insurance and customs purposes [5]. Firstly, the receipt of cargo is issued by the carrier after the goods were loaded onto the ship and serves as proof that the carrier has received the cargo that was mentioned in the BOL. According to international conventions, such as the Hague Visby Rules and the Hamburg Rules [4, 6], BOL is conclusive evidence from the moment it is transferred to a third party. Furthermore, the BOL provides information about the cargo, such as quantity, condition, weight and description [7, 8]. Consequently, the cargo has to match the receipt and the stated information at the port of destination. Thirdly, according to Girvin [7] the receipt prevents the declaration of previous damage by the carrier. Therefore, when the cargo with insufficient condition or quantity is received by the consignee, the shipper has the possibility to hold the carrier accountable. However, when the carrier can prove that the received goods have insufficient quality, the shipper is accountable for loss and damage [7].
Therefore, the BOL can be used as evidence for insurance and customs purposes.

\section{2) Evidence of contract of carriage}

Another important function of the BOL is the evidence of the contract of carriage, which is not the contract of carriage itself. According to Rotterdam Rules (2009) 'Contract of carriage' means a contract in which a carrier, against the payment of freight, undertakes to carry goods from one place to another [9]. The BOL follows the contract of carriage, but the actual contract of carriage between the carrier and the shipper, is determined when the goods are loaded on board the vessel and therefore exists before the BOL is issued [10]. When preparing the BOL, it is implicitly assumed that a contract has already been concluded.

\section{3) Document of Title}

The document of title is the third legal function of the BOL. This function enables the BOL to play a central part in international trade [11]. According to Dubovec [10], the document of title can be categorised in three procedures. The first procedure is the passing of ownership of cargo to a third party. Secondly, confirmation of possession and physical control over cargo is controlled by this function. Finally, the last procedure of the document of title is security for creditors.

First, the BOL is a negotiable document of title. That means that the document enables the transfer of ownership of the cargo to a third party. Therefore, the transfer of the BOL is equal to the transfer of possession of the goods [10]. This is because the cargo cannot be physically delivered while in transit. Thus, the endorsement and delivery of the BOL represents the "symbolic" delivery of the cargo [12]. Furthermore, the cargo can be bought and sold while it is still in transit [12]. This kind of operation is common practice in international commerce. According to Schmitz [12], oil, for example, can switch its buyer 20 to 30 times before it arrives at the port of destination. Secondly, the holder of the BOL obtains "constructive possession" of the goods once arrived at the destination [12]. Constructive possession thus refers to the legal ownership of the cargo, while the carrier has the physical possession. Finally, according to Dubovec [10] when the BOL arrives after the goods, the consignee can present a letter of indemnity (LOI) from his bank to receive the goods. Once the $\mathrm{BOL}$ arrives the consignee provides the BOL to the carrier to relieve the consignee and the bank from the liabilities posed by the LOI.

\section{ELECTRONIC BILL OF LADING}

The electronic Bill of Lading (eBOL) represents the legal and functional equivalent of the paper BOL [13]. However, the simple scanning and copying of a traditional BOL is not considered an eBOL. Schmitz [12] defines eBOL as a type of BOL which is based on computer or electronic technology. According to Alawamleh [13], the eBOL has been created especially to eliminate the flaws of the traditional BOL such as slowness, fraud and cost. The advance in globalisation and shift in customer demand, indicate the limitations of the paperbased BOL.

Faster vessels and quick turn-around times do not comply with the traditional BOL anymore $[13,14]$. It has to be handled by many different parties and individuals and thus creates slowness and therefore, the BOL might arrive at the consignee after the arrival of the goods. Already in 1999, Nicoll [15] 
declared the traditional BOL as an "outmoded technology", due to its slowness. In addition to that, a paper BOL is open to all kinds of manipulations. For example, falsified BOLs can be used to falsely claim the goods. According to Bury [16], paper documents are easy to forge. Since the carrier is obliged to deliver the document to the holder of a BOL, this circumstance can be used for fraud. Furthermore, the conventional BOL entails considerable costs.

First of all, the BOL has to be sent securely and fast through the postal way. According to Wunderlich and Saive [17], the obligations regarding the documentation, including the Bill of Lading, account for $5-10 \%$ of the total costs of transport. Secondly, if the BOL is not in the right place at the right time, the shipment cannot be collected [13]. Moreover, more than 20 million containers are shipped continuously across the oceans per year [18]. According to Ziakas [14], $\$ 420$ bn are spent on shipping documents each year, and with an electronic alternative, these costs could be reduced by $50 \%$.

However, the global implementation of the eBOL is not yet realisable. As Takahashi [19] points out, $44 \%$ of a study conducted by the United Nations among actors in maritime logistics stated that the lack of a legal framework is a significant obstacle to the digitalisation of the traditional BOL. Therefore, the biggest barrier to a successful implementation is the lack of knowledge of already in place standards and regulations. Other barriers mentioned are the lack of trust of information systems [20] and the fear of increased fraud [19]. According to Ziakas [14], eBOL has to acquire the recognition of a court so it can be used legally. Hence, in a first step, this paper sets out to analyse the most important regulations that support a possible digitalisation of the BOL. Secondly, these regulations don't only have to support the digitalisation of the BOL, but also its three main functions, such as the evidence of the contract of carriage, the receipt of goods and the document of title.

\section{A. Supporting standards and regulations}

This paragraph addresses the three main standards and regulations which support the digitalisation of the traditional BOL. It will focus first on the Rotterdam Rules (RR). In what follows, the Model Law on Electronic Transferable Records (MLETR) will be discussed. Finally, the Electronic Data Interchange (EDI) will be looked at.

\section{1) The Rotterdam Rules}

First of all, the Rotterdam Rules (2008) [9] provide a legal basis that legitimises electronic forms of transport documents and permits them as alternatives of equal value to paper documents. RR does not refer to an eBOL directly but defines the term of "negotiable electronic transport record". In order to establish the equal treatment of paper documents and substitutes in electronic form, requirements of article 9 must be met [9].These requirements are "the method for the issuance and the transfer of that record to an intended holder", "an assurance that the [...] record retains its integrity", "the manner in which the holder is able to demonstrate that it is the holder" and "the manner of providing confirmation that delivery to the holder has been effected or that the electronic transport record has ceased to have any effect or validity" [9].

The first requirement of a negotiable electronic transport record is outlining methods for issuance and transfer to a holder $[9,21]$. In the context of the RR, both issuance and transferability include the requirement to ensure exclusive access for the respective holder and the uniqueness of the data. In the digital world, however, the attribute of the uniqueness of documents does not exist. Secondly, ensuring the integrity of documents is a crucial aspect that the RR refer to [9, 21]. The traditional BOL is ensuring its integrity by the handwritten signatures attached to endorsements. Thus, any used technology that handles the negotiable record has to offer an equivalent alternative to the signature. Thirdly, the mechanism for detecting possession of a document is an essential requirement to take into account $[9,21]$. One of the processes for which the BOL is used is the receipt of the goods at their destination by the consignee. In the paper-based process, the consignee receives an original of the BOL and must be able to present it in order to receive the freight [16]. By possessing an original, the recipient proves that he is authorized to receive the goods. In order to enable this process over a digital medium, this must possess a mechanism, which makes it possible for an actor to prove the possession of a document or data record. Finally, confirmation of arrival and withdrawal of the legal effect of a document is the last requirement article 9 is mentioning $[9,21]$. The last requirement for a technology to handle Negotiable Electronic Transport Records within the meaning of the Rotterdam Rules deals with mechanisms that ensure that documents lose their legal effect after the conclusion of the associated business transaction. Similar to the paper-based BOL, which loses its effect as a security for the goods after receipt of the goods by the consignee and handover of the document to the carrier, the technology must offer an equivalent mechanism. When all 4 abovementioned requirements are fulfilled, the eBOL is qualified as a "negotiable electronic transport record" within the meaning of the Rotterdam Rules.

\section{2) Model Law on Electronic Transferable Records}

MLETR establishes rules to allow the electronic equivalent of the paper-based BOL to be legally recognised $[22,23]$. However, the term "Model Law" signifies that UNICTRAL is providing a legal framework which can be used by any national legislatures when preparing national laws on this topic. Three different principles were taken into account when this regulation was drafted, namely non-discrimination, functional equivalence and technology neutrality [22]. Firstly, the non-discrimination principle is regarding "a document [that] would not be denied legal effect, validity or enforceability solely on the grounds that it is in electronic form". Secondly, the functional equivalence principle states the situation "under which electronic communications may be considered equivalent to paper-based documents". Finally, the last principle "technology neutrality" "provide[s] for the coverage of all factual situations [...] irrespective of the technology or the medium used". [22]

According to MLETR an electronic document is a functionally equivalent rule to a paper-based document when 4 provisions (appendix 2) are fulfilled. The provisions refer to writing (article 8), signature (article 9), transferable documents or instruments (article 10) and Control (Article 11) $[22,23]$. First of all, chapter 2 of MLETR determines the functional equivalence of the written form. Secondly, a requirement of any signature can be substituted by any functional equivalent alternative or mechanism. Thirdly, article 10 deals with the notion of uniqueness of any transferable document. The uniqueness prevents the 
circulation of multiple documents which would induce multiple claims. However, achieving uniqueness is a challenge in the digital world. Therefore, MLETR provides functional equivalence to uniqueness by presenting two different concepts, namely singularity and control (article 11). According to the Model Law, the singularity approach focuses on the identification of electronic transferable record. Furthermore, article 10 states that every electronic record should contain the same information that are required in any other paper-based, transferable record. Finally, the notion of control is defined as using a reliable method that clearly identifies the person in control of the transferable record. This set of regulations takes into account essential legal aspects to any electronic communication, such as the eBOL. Thus, when relevant criteria, outlined in Chapter 2 of UNCITRAL, are fulfilled, a transferable electronic record can be deemed legally valid [23].

\section{3) Electronic Data Interchange}

The electronic data interchange (UN/EDIFACT) is a set of standards that provide data structures and rules to support the design of exchange protocols and standardised messages [24]. EDI aims to create a multi-user system which connects all important parties in one network and ensures that data is transmitted correctly between parties [16]. Firstly, EDI are standards that allow data to be transmitted directly between different computer systems with the help of a combination of technology and management resources. If two computers have the same EDI standards, the message is transmittable and available right away on the receiving computer. However, when the standards and the software differ, a third-party network supports the translation between the different standards $[16,25,26]$. Furthermore, EDI is applicable in the shipping industry. Shipping documents can be transferred by using EDI [25]. Thus, the carrier creates the document and transmits it to the shipper. The transmission provides the shipper with a unique, private key that can be used to transfer the electronic document to other third parties which are in the same multi-user system. Consequently, the transmission with the help of the private key enables the authenticity and integrity of the document [25]. In conclusion, EDI is a method that supports the electronic transfer of data within a system. However, EDI needs to be incorporated into a legal framework. One legal issue that has to be incorporated in any EDI system is an alternative to the signature of any document. This is essential to increase trust and authentication in any system. The Hamburg Rules [4] state that the signature on the BOL might be in "handwriting, $[\ldots]$ or made by any other mechanical or electronic means". Thus, the electronic signature can be incorporated while using EDI besides other identification information, such as name and private key. Furthermore, an electronic signature is secured by the use of cryptography, which prevents third parties to read the associated data [26].

The presented laws should not only support the digitalisation of the BOL but also the three main functions, namely evidence of the contract of carriage, receipt of goods and the document of title. Table 1 presents the criteria which any form of eBOL has to fulfil in order to be a legal equivalent to the traditional BOL. These criteria are categorised according to three main functions and the following table represents a summary of these functions.
The first two criteria are related to the first function of the BOL. The carrier has to issue a receipt to the shipper, which includes all the important information. Furthermore, the consignee should have the possibility to compare the handed over cargo with the information stated on an electronic document. To fulfil the second function and the third criteria, the electronic document has to include clear evidence of a contract of carriage or should refer to one. Moreover, the eBOL has to support the transfer of ownership.

\section{B. Criteria for the digitalisation of the eBOL}

The presented laws should not only support the digitalisation of the BOL but also the three main functions, namely evidence of the contract of carriage, receipt of goods and the document of title. Table 1 presents the criteria which any form of eBOL has to fulfil in order to be a legal equivalent to the traditional BOL. These criteria are categorised according to three main functions and the following table represents a summary of these functions.

The first two criteria are related to the first function of the BOL. The carrier has to issue a receipt to the shipper, which includes all the important information. Furthermore, the consignee should have the possibility to compare the handed over cargo with the information stated on an electronic document. To fulfil the second function and the third criteria, the electronic document has to include clear evidence of a contract of carriage or should refer to one. Moreover, the eBOL has to support the transfer of ownership.

TABLE 2. CRITERIA FOR THE ELECTRONIC BOL

\begin{tabular}{|c|cc|}
\hline Function & \multicolumn{1}{c|}{ Criteria } \\
\hline $\begin{array}{c}\text { Receipt of } \\
\text { Cargo }\end{array}$ & $\begin{array}{c}\text { 2. } \\
\text { Carrier has to issue a receipt to the shipper, } \\
\text { which refers to the important information of } \\
\text { the cargo }\end{array}$ \\
\hline $\begin{array}{c}\text { The consignee has to acquire the possession of } \\
\text { the cargo and compare cargo with the } \\
\text { information stated on the receipt }\end{array}$ \\
\hline $\begin{array}{c}\text { contract of } \\
\text { carriage }\end{array}$ & 3. & $\begin{array}{l}\text { The document has to include clear evidence of } \\
\text { the contract of carriage or a reference to it }\end{array}$ \\
\hline $\begin{array}{c}\text { Document of } \\
\text { Title }\end{array}$ & 4. $\begin{array}{l}\text { Support of the transferring process of BOL } \\
\text { ownership to a third party }\end{array}$ \\
\hline
\end{tabular}

\section{DISCUSSION}

To fully support the eBOL a sufficient support from the legal infrastructure is necessary, so that every party involved, including banks, accepts the eBOL as collateral. The first 2 functions can easily be covered by the regulations mentioned, Rotterdam1 Rules and MLETR. In particular, a BOL that covers only the first two function is defined as a straight or non-negotiable BOL. According to Delmedico [27] nonnegotiable BOL, such as sea waybills, are already implemented electronically. The sea waybill is a nonnegotiable document that has the functions of the receipt of cargo and the evidence of contract, and identifies the person who receives the cargo [28]. There is no need to sell the cargo 
while it is in transit and it is used where the goods have been paid for. Non-negotiable BOL, therefore, implements only two out of the three functions of a negotiable BOL, namely evidence of contract of carriage and cargo receipt. Furthermore, the possession of this kind of BOL is not equal to the title of the goods. That means that the straight bill does not act as security. This kind of BOL is consigned to a specific person. Thus, the seller uses a certain transportation mode to ship the goods to a specific location with a specific third party that acquires the BOL. Since the BOL is not negotiable, it cannot be re-assigned to another party.

However, the implementation of negotiable BOL have encountered some problems regarding the transferability. The element of negotiability in form of transferability is fundamental for a BOL acting as the function of document of title. The MLETR provides article 10 regarding a transferable document. The MLETR provides two provisions of singularity and control that support the transfer of an electronic document. The RR requires a mechanism that identifies the owner. If that mechanism complies according the RR, this criterion is fulfilled as well. Furthermore, the integrity of the document is regulated and discussed in both RR and the MLETR. The integrity of an electronic document is compliant to the RR when the offered technology provides an equivalent of the written signature. The MLETR provides the article 9 (signature), which states that any signature can be substituted by any functional equivalent alternative. The Rotterdam Rules and the MLETR provide, thus, the necessary provisions for a digitalisation of the eBOL, because they support the digitalisation of three main functions.

The RR is linked to the fact that all participating actors act based on the legislation of states that have signed the RR and have incorporated them into their national legislation. The rules require enough ratification to be adapted successfully in the international community. This is not yet applicable (2019). Because of this limitation, it is essential to look at different regulations that have the potential to support the acquisition of the recognition of the court. Moreover, the MLETR has the potential to ensure compliance for any kind of electronic document and supports the digitalization of an eBOL. However, as abovementioned a Model Law is providing a legal framework for any national legislatures and not regulations themselves. Finally, the EDI Standards support, with the support of rules and data structures, a multi-user system that connects all important parties, which is already used in the shipping industry. However, the implementation of an EDI eBOL requires an external company that provides the necessary trust and infrastructure to implement an eBOL. Besides, only companies which are part of this EDI multi-user system can use the eBOL function of the trusted third-party company. This means that a large number of interested parties are excluded.

\section{CONCLUSION}

In conclusion, this literature review first discussed the most essential eleven elements most of the BOLs have in common. Furthermore, three main functions of the BOL were presented, namely receipt of cargo, evidence of carriage and document of title. However, due to its slowness, high costs and increasing possibility of fraud, there is a need for alternatives to the traditional BOL. Thus, this paper discussed the advantages of the eBOL, but also the reasons why the eBOL's global implementation has not yet been realized.

In order to fully implement the eBOL the three main functions of the BOL have to be digitalised as well. That is why four criteria, any eBOL has to fulfil in order to be legally valid, were defined. Furthermore, every electronic document has to be compliant to a legal framework or standards. Hence, the Rotterdam Rules and MLETR and their importance were illustrated in this literature review. MLETR and the Rotterdam Rules support the digitalisation of eBOL and the four defined criteria. However, both laws cannot be implemented without concern as there are still some barriers to overcome. First and foremost, MLETR is limited as a guideline to national legislatures. Secondly, the Rotterdam Rules have not yet been supported by enough countries to be ratified and adapted internationally. The EDI standards support the eBOL in a multi-user system with their own rulebook. Nevertheless, beyond the boundaries of the system, the eBOL has not been recognised yet.

While this literature review solely focused on the supporting legal framework it did not address the digitalisation of the BOL itself. The necessary technology which is needed for the implementation of the eBOL while also fulfilling the regulations was thus not discussed. Furthermore, countries which adopted the MLETR in their national laws should be identified in future research in order to illustrate which countries can support a global eBOL.

\section{REFERENCES}

[1] Alphaliner. "Alphaliner TOP 100." Alphaliner. https://alphaliner.axsmarine.com/PublicTop100/ (accessed 20th July 2019)

[2] Protocol to Amend the International Convention for the Unification of Certain Rules of Law Relating to Bills of Lading (The Hague-Visby Rules), 1412 UNTS 127, 1968.

[3] International Federation of Freight Forwarders Associations (FIATA). "Documents." Fiata. https://fiata.com/about-fiata/fiata-documents.html (accessed 20th July 2019, 2019).

[4] UNITED NATIONS CONVENTION ON THE CARRIAGE OF GOODS BY SEA (Hamburger Rules), U. Nations UN Doc. A/CONF.89/13, 1978.

[5] C. Proctor, The legal role of the bill of lading, sea waybill and multimodal transport document. Interlegal, 1997.

[6] B. W. Yancey, "Carriage of Goods: Hague, Cogsa, Visby, and Hamburg," Tul. L. Rev., vol. 57, p. 1238, 1982.

[7] S. Girvin, Carriage of goods by sea. Oxford University Press Oxford, 2007.

[8] M. R. A. Ahmadi, M. Elsan, and I. Noshadi, "Comparative Study of Bill of Lading Function as Title Document," J. Pol. \& L., vol. 10, p. 188, 2017, doi: 10.5539/jpl.v10n1p188.

[9] United Nations Convention on Contracts for the International Carriage of Goods Wholly or Partly by Sea (Rotterdam Rules), U. Nations A/RES/63/122, 2008.

[10]M. Dubovec, "The problems and possibilities for using electronic bills of lading as collateral," Ariz. J. Int'l \& Comp. L., vol. 23, p. 437, 2005.

[11]H. M. Kindred, "Modern Methods of Processing Overseas Trade," Journal of World Trade, vol. 22, no. 6, pp. 5-17, 1988.

[12]T. Schmitz, "The bill of lading as a document of title," Journal of International Trade Law and Policy, vol. 10, no. 3, pp. 255-280, 2011, doi: 10.1108/14770021111165526.

[13] K. Alawamleh, "TRADITIONALS BILLS OF LADING V. ELECTRONIC BILLS OF LADINGS: PROS AND CONS AND THE WAY FORWARD," in 64th The IRES International Conference, Oxford, UK, 2017.

[14] V. Ziakas, "Challenges Regarding the Electronic Bill of Lading (eBoL)," International Journal of Commerce and Finance, vol. 4, no. 2, p. 40, 2018 . 
[15]C. Nicoll, "BOLERO Makes the Bill of Lading Obsolete," INTERNATIONAL MARITIME LAW, vol. 6, pp. 148-152, 1999.

[16]D. A. Bury, "Electronic bills of lading: a never-ending story," Tul. Mar. $L J$, vol. 41, p. 197, 2016.

[17] S. Wunderlich and D. Saive, "The Electronic Bill of Lading," Prieto J., Das A., Ferretti S., Pinto A., Corchado J. (eds) Blockchain and Applications. BLOCKCHAIN 2019. Advances in Intelligent Systems and Computing, vol. 1010, pp. 93-100, doi: 0.1007/978-3-030-23813-1_12.

[18] Alphaliner. "Alphaliner TOP 100." Alphaliner. https://alphaliner.axsmarine.com/PublicTop100/ (accessed 20th July, 2019).

[19]K. Takahashi, "Blockchain technology and electronic bills of lading," The Journal of International Maritime Law Published by Lawtext Publishing Limited, vol. 22, pp. 202-211, 2016.

[20]O. Ajaja, "Electronic Bills of Lading: An Easier Way to Sea Carriage," Available at SSRN 2707960, 2015, doi: 10.2139/ssrn.2707960.

[21]R. Stahlbock, L. Heilig, and S. Voß "Blockchain in maritime logistics (Blockchain in der maritimen Logistik)," HMD Praxis der Wirtschaftsinformatik, vol. 55, no. 6, pp. 1185-1203, 2018, doi 10.1365/s40702-018-00464-8.
[22] UNCITRAL, "Explanatory note to the UNCITRAL model law on electronic transferable records," UNCITRAL Model Law on Electronic Transferable Records, 2017, doi: https://doi.org/10.18356/132ff762-en.

[23] H. D. Gabriel, "THE UNCITRAL model law on electronic transferable records," Uniform Law Review, 2019, doi: 10.1093/ulr/unz013.

[24] A. Pagnoni and A. Visconti, "Secure electronic bills of lading: blind counts and digital signatures," Electronic Commerce Research, vol. 10, no. 3-4, pp. 363-388, 2010, doi: https://doi.org/10.1007/s10660-0109060-2.

[25] G. JANSSENS, "Electronic data intercharge: From its birth to its new role in logistics information systems," 2011

[26] K. Meadors, "Secure electronic data interchange over the Internet," IEEE Internet Computing, vol. 9, no. 3, pp. 82-89, 2005, doi: 10.1109/MIC.2005.66.

[27]A. Delmedico, "EDI Bills of Lading: Beyond Negotiability," Hertfordshire Law Journal.[Online], vol. 1, no. 1, pp. 95-100, 2003.

[28] P. G. Pamel, R. C. Wilkins, and L. Borden Ladner Gervais, "Bills of Lading vs Sea Waybills, and The Himalaya Clause," in NJI/CMLA, Federal Court and Federal Court of Appeal Canadian Maritime Law Association Seminar, 2011 